\title{
Implementation of Breastfeeding Friendly Policy in a Factory: A Qualitative Study among Occupational Health and Safety Coordinators in Indonesia
}

\author{
Ray Wagiu Basrowi ${ }^{1}$, Sudigdo Sastroasmoro ${ }^{2}$, Astrid W Sulistomo ${ }^{1}$, Saptawati Bardosono ${ }^{3}$, \\ Aryono Hendarto ${ }^{2}$, Ali Sungkar ${ }^{4}$, Dewi S Soemarko ${ }^{1,5}$ and Yvan Vandenplas ${ }^{6 *}$ \\ ${ }^{1}$ Occupational Medicine Division, Department of Community Medicine, Indonesia \\ ${ }^{2}$ Department of Child Health, Indonesia \\ ${ }^{3}$ Department of Nutrition, Indonesia \\ ${ }^{4}$ Department of Obstetric Gynecology, Indonesia \\ ${ }^{5}$ Occupational and Environmental Health Research Cluster, Indonesia \\ ${ }^{6}$ KidZ Health Castle, UZ Brussel, Belgium \\ *Corresponding author: Yvan Vandenplas, KidZ Health Castle, UZ Brussel, Vrije Universiteit Brussel, Laarbeeklaan 101 - 1090 \\ Brussel, Belgium
}

\section{ARTICLE INFO}

Received: 幽 December 13, 2019

Published: 幽 January 06, 2020

Citation: Ray Wagiu B, Sudigdo S, Astrid W S, Saptawati B, Yvan Vandenplas, et al., Implementation of Breastfeeding Friendly Policy in a Factory: A Qualitative Study among Occupational Health and Safety Coordinators in Indonesia. Biomed J Sci \& Tech Res 24(1)-2020. BJSTR. MS.ID.004004.

Keywords: Breastfeeding; Lactation; Occupational Health and Safety; Women Workers

\section{ABSTRACT}

Background: Not all mothers are able to breastfeed or pump milk. Return-towork has been identified as a major and significant barrier to continue breastfeeding, due to improper lactation facilities at the workplace. This study aimed to explore the implementation of breastfeeding friendly policy at factories, from the perspective of Occupational Health and Safety (OHS) coordinators.

Methods: A qualitative survey conducted in eight factories, using an adjusted openended questionnaire to OHS coordinators in manufacture and garment factories in an industrial area in East Jakarta. The results are presented in a descriptive display matrix and listing, without any statistical analysis. Key and most relevant suggestions and inputs from respondents are presented in the form of quotations to support the pattern found from the survey.

Results: Eight respondents in-charge for the occupational health and safety division participated in this study; all worked in the current factory for more than five years, and four of them were medical doctors. All respondents reported that their factory formally implemented the governmental regulations. However, three respondents reported that their factory provided a multifunctional lactation room, shared with the company's clinic. All of the factories granted a flexible breast-pumping break time during working hours, but only one respondent reported an annual lactation education class provided in the factory. None of the respondents reported a nutrition intervention and dedicated lactation counselor provided in their factories.

Conclusion: This qualitative study among OHS coordinators in factories revealed that there is still lack of breastfeeding friendly policy implementation in factories.

\section{Introduction}

Exclusive breastfeeding is the best nutrition source of infants. The World Health Organization (WHO) and the Ministry of Health of Indonesia recommend exclusive breastfeeding for the first 6 months of life which should be continued with complimentary food for two years [1-3]. WHO defines exclusive breastfeeding as an infant that only receives breastmilk without any other foods, 
including any liquids, water, formula milk, fruit juice, tea, honey, or any solid food except vitamins and medicines [1,4]. Exclusive breastfeeding is not only beneficial for the infants, but also the mothers. Breastfeeding helps to reduce post-partum body weight and the risk for non-communicable diseases, [5-8] cardiovascular disease [9]. Breastfeeding improves the quality of life of the mother and her mental health [10]. Breastfeeding prolongs the amenorrhea period [11]. However, not all mothers are able to breastfeed, especially the working mother population. Return to work after maternal leave has been identified as a major and significant barrier for women workers to continue breastfeeding. Studies show that the breastfeeding rate significantly decreases at the time when mothers return to work $[12,13]$.

The main reasons are related to the distance between home and workplace, improper lactation facilities at the workplace and decreased breastmilk production during working hours [14]. The prevalence of exclusive breastfeeding among factory workers in 2015 was only $19 \%$, significantly lower compared to the national prevalence which was 38\% [15]. A study in Taiwan showed that only $10.6 \%$ of working mothers continue to breastfeed upon returning to work [14]. An Indonesia study found that $45 \%$ of working mothers discontinue breastfeeding because of return-to-work. Inadequate lactation facilities and support programs in workplace are the main reasons of discontinuation [12]. In Indonesia the breastfeeding and lactation competency is not part of the basic and required competency of corporate physicians, company doctors and Occupational Health and Safety (OHS) coordinators, who in fact are responsible for the health promotion program at the workplace $[16,17]$. According to Cochrane Reviews in 2012, no randomized controlled trial has been performed to evaluate the effectiveness of a workplace lactation intervention program [18]. The present article is a report of a survey of OHS coordinators in eight factories in the East Jakarta region. This qualitative study aimed to identify the OHS coordinator's perspective about the implementation of national breastfeeding friendly policy and breastfeeding promotion support in their respected factory.

\section{Methods}

This is a qualitative survey conducted in eight factories in Jakarta, using an adjusted open-ended questionnaire [19]. The study population were eight OHS coordinators in manufacture and garment factories in an industrial area in East Jakarta. The respondents were asked to fill a questionnaire that consisted of four basic questions, i.e, 'what is the current situation of breastfeeding policy implementation in your workplace'; 'what are the current services, program, facilities, and support toward lactating employer in your respected company'; 'what are the specific internal company's regulation/policy on breastfeeding promotion'; and 'what are your practical assessment/evaluation toward breastfeeding promotion support in your respected company'. Since the number of subjects or respondents is too low to perform any statistical test, the result of this survey aimed to list and report the patterns, similarity, and factual findings within the relevant answers of the respondents. Data obtained from the questionnaires were presented in a descriptive display matrix, listing all the information from the respondents coded as subject 1 to subject 8 . The key and most relevant suggestions and inputs from respondents are presented in the form of quotations to support the pattern found from the survey. This study was approved by The Ethics Committee of Faculty of Medicine of the authors' institute, letter number XXX/XXX.F1/XXXX/2016.

\section{Results}

Appendix Tables 1-3 shows that all respondents have worked in the current factory for more than five years and $50 \%$ of them were medical doctors. All respondents were in the possession of an occupational and workplace health and safety certification required for an OHS coordinator. However, only one respondent obtained a certificate for a specific training in lactation/breastfeeding promotion. The initial response of all respondents mentioned the implementation of the breastfeeding policy formally implemented the government regulation in their factory. However, when it comes to the availability of a dedicated lactation room, three respondents reported that their factory provided a multifunction lactation room, shared with the company's clinic. Descriptively, three respondents responded affirmatively that providing breastfeeding facility in workplace was mainly determined by the financial assessment and profitable consideration of the factory.

"Breastfeeding facilities provided in the factory based on the standard guideline of the Labor Ministry and Health Ministry regulation, which is also giving the space and opportunity to the company/factory to make the support available at the basic standard, to be fit with the scale and affordability of the company. It is also understandable that providing breastfeeding policy is not considered as profit investment hence fulfilling the breastfeeding support at the minimum required facility is acceptable"

On the maternal leave policy, all respondents reported that their factories implemented the minimum required policy regulated by Labor Ministry of the Republic of Indonesia which is three months leave and the employee should have started to take leave 1.5 month prior to delivery due date. Upon return to work from maternal leave, all factories granted a flexible breast-pumping break time to a lactating employee during working hours with certain conditions such as pumping time break should be authorized by a supervisor. The employee is advised to maximize the lunch break time for pumping. Nevertheless, one respondent admitted that additional pumping break times apart of the lunch break are needed. During the pumping break, the workload should be covered by other colleagues.

"Company guaranteed and committed to provide flexible working hours to the lactating employee and fully understand that this group of employees will require more time to breastfeeding or breast pumping, a part of the lunch time break. This situation is unique and 
hence the employee will not be sanctioned for leaving the job more often"

On the type of breastfeeding promotion, education program and materials in the workplace, four respondents reported that their factories provided no education program and materials related to breastfeeding and lactation. Three respondents reported that their factories provided breastfeeding education materials such as posters, booklets and leaflets in the lactation room and clinic, and only one respondent reported an annual lactation education class provided in the factory. None of the respondents reported a nutrition intervention for lactating employees provided in their factories. None did hire a dedicated lactation counselor, and none reported a special reward program towards breastfeeding According to all respondents, the abovementioned services or policies remain absent mainly because those were not formally stated in the current national breastfeeding friendly policy. All respondents acknowledged that their company fulfilled only the minimal governmental requirements. One respondent mentioned that the factory usually does not provide health services beyond the minimal recommended governmental requirements:

"It is common that the management of the factory will only follow the points that are stated and recommended by the governmental policy, because the company has limited knowledge and technical competence to go beyond the regulation, hence is unable to modify the guideline in health promotion services at the workplace, including breastfeeding promotion and support."

Similar findings were reported regarding the remuneration system. All applied the same incentive scheme independent from the fact if the employee was lactating or not, without compromising their need of additional break time for pumping.

\section{Discussion}

To the best of our knowledge, this is the first study reporting on the implementation of the breastfeeding friendly policy in a factory, explored from the perspective of OHS coordinator in Indonesia. This study reported that the implementation of national or governmental breastfeeding friendly policy in factories is still not optimal compared to what had been suggested by the referenced guidelines and recommendations. The availability of a dedicated and private lactation room is the prioritized facility regulated by the policy, and still there are three out of eight factories that only provide a multi-functional room. The availability of a dedicated and private lactation room is one of the key factors to support the continuation of exclusive breastfeeding among working mothers [19-21]. Failure in providing a private and dedicated lactation room at work not only increases the probability of breastfeeding cessation but should also be a non-compliance of employers, hence requiring control and monitoring by the regulator.

Maternal leave is also another indicator explored in this study, and we found that all eight factories only fulfilled the minimum requirements of three months maternal leave and obliged the workers to take leave at least 1.5 months before delivery duedate, which means the workers will need to return to work when the infants are only 1.5-month-old. Although this is not against the policy, it creates a challenging situation for the working mothers. Previous studies suggested that it is advisable for the employer to lengthen the leave duration whenever possible [19,22-25]. Flexible time of breast pumping breaks during working hours is another recommended item by the government policy, endorsed by evidence $[21,26,27]$. Findings from this study showed that this policy was implemented, although few reiterated the importance of getting permission from a supervisor as well as a suggestion to workers to maximize the lunch break time to pump. The government has made it obligatory to provide a breastfeeding facility in workplace and it was recommended by The Indonesian government through a Joint Regulation since 2008 [28].

Other findings from this study also showed that breastfeeding promotion, education programs, and materials support in workplace were not fully implemented. This finding is similar with another study in Indonesia reporting that only $21.5 \%$ of workers have access to proper lactation facilities at work [15]. Most respondents also mentioned that their factories only distributing leaflet and posters related to breastfeeding, while this conservative support was found to be less effective [15,25]. Respondents also admitted that the management and/or factory owners have put the profitability and financial consideration as the key determined parameter in providing breastfeeding facilities and support program at work. This is consistent with findings from the previous study reported that employers do not prioritizing breastfeeding support at the workplace for many reasons [29]. The lack of breastfeeding facilities and support programs will hamper the working performance and productivity of lactating workers $[30,31]$. All respondents also reported that none of the factories provided a dedicated lactation counsellor at the workplace as it is not clearly recommended by the governmental policy.

A study in Thailand reported that an education co-operation platform of health professionals, the manager and other representatives from the management should be set up, with the support by nurse-midwives and/or lactation consultants within the workplace [32]. Occupational and environmental health nurses trained with specific breastfeeding knowledge also could improve the success of breastfeeding [31] Many studies have shown that an employer could benefit from their female workers' breastfeeding and lactation behaviour which would improve the employee's productivity and motivate mothers to return to work [33-37]. Transforming a workplace to become a breastfeeding friendly environment is critical to support lactating workers [38].

\section{Conclusion}

It is evidence based that supporting working mothers to continue breastfeeding at work will be beneficial for the infants, 
workers, and the employers. Hence, it is recommended by an established governmental policy. However, this qualitative study among OHS coordinators in factories revealed that there is still lack of breastfeeding friendly policy implementation in factories due to misperception of employers toward breastfeeding benefits.

\section{Key-Message}

1. There is a lack of breastfeeding friendly policy implementation in factories.

2. Employers have an erroneous perception of breastfeeding benefits on their employees, breastfeeding mothers.

\section{Ethics}

This study was approved by The Ethics Committee of Faculty of Medicine, Universitas Indonesia, letter number 786/UN2.F1/ ETIK/2016.

\section{Conflict of Interest}

RWB is employee of Nestle Nutrition Institute. YV has participated as a clinical investigator, and/or advisory board member, and/or consultant, and/or speaker for Abbott Nutrition, Danone, Nestle Health Science, Nestle Nutrition Institute, Nutricia, Mead Johnson Nutrition, United Pharmaceuticals, Wyeth. Other authors declared no conflict of interest.

\section{Funding Disclosure}

This study received no external funding.

\section{References}

1. Exclusive breastfeeding for optimal growth, development and health of infants. In: World Health Organization.

2. Riordan J (2005) Breastfeeding and human lactation ( $3^{\text {rd }}$ edn.). Sudbury, MA: Jones \& Bartlett Learning.

3. (2013) Improving child nutrition: The achievable imperative for global progress. In: New York, United Nations.

4. (2003) Global strategy for infant and young children feeding. In: World Health Organization, Geneva.

5. Fraser AB, Grimes DA (2003) Effect of lactation on maternal body weight: a systematic review. Obstet Gynecol Surv 58(4): 265-269.

6. López Olmedo N, Hernández Cordero S, Neufeld LM, García Guerra A, Mejía Rodríguez F, et al. (2016) The associations of maternal weight change with breastfeeding, diet and physical activity during the postpartum period. Matern Child Health J 20(2): 270-280.

7. Smith DE, Lewis CE, Caveny JL, Perkins LL, Burke GL, et al. (1994) Longitudinal changes in adiposity associated with pregnancy. The CARDIA Study. Coronary Artery Risk Development in Young Adults Study. JAMA 271(22): 1747-1751.

8. Janney CA, Zhang D, Sowers M (1997) Lactation and weight retention. Am J Clin Nutr 66: 1116-1124.

9. Kelly KM, Chopra I, Dolly B (2015) Breastfeeding: an unknown factor to reduce heart disease risk among breast- feeding women. Breastfeed Med 10(9): 442-447.

10. Chojenta CL, Lucke JC, Forder PM, Loxton DJ (2016) Maternal health factors as risks for postnatal depression: a prospective longitudinal study. PLoS One 11: e0147246.
11. Chowdhury R, Sinha B, Sankar MJ, Taneja S, Bhandari N, et al. (2015) Breastfeeding and maternal health outcomes: a systematic review and meta-analysis. Acta Paediatr 104(467): 96-113.

12. Abdullah GI, Ayubi D (2013) Determinan perilaku pemberian air susu eksklusif pada ibu pekerja. J Kesmas 7(7): 298-303.

13. Wulandari E (2010) Effect of lactation education at work on self-efficacy of exclusive breastfeeding for women of childbearing age: Case study at the 2010 Chevron IndoAsia Business unit in Jakarta [thesis]. Depok: Universitas Indonesia.

14. Chen YC, Wu YC, Chie WC (2006) Effects of work-related factors on the breastfeeding behavior of working mothers in a Taiwanese semiconductor manufacturer: a cross- sectional survey. BMC Public Health 6: 160 .

15. Basrowi RW, Sulistomo AW, Adi NP, Vandenplas Y (2015) Benefits of a dedicated breastfeeding facility and support program for exclusive breastfeeding among workers in Indonesia. Pediatr Gastroenterol Hepatol Nutr 18(2): 94-99.

16. Harianto R (2012) Buku ajar kesehatan kerja. Jakarta, Indonesia.

17. Kurniawidjaja LM (2010) Teori dan aplikasi kesehatan kerja. UI Press: Jakarta, Indonesia.

18. Abdulwadud OA, Snow ME (2012) Interventions in the work- place to support breastfeeding for women in employment. Cochrane Database Syst Rev 10: CD006177.

19. Basrowi RW, Sastroasmoro S, Sulistomo AW, Bardosono S, Hendarto A, et al. (2018) Developing a workplace lactation promotion model in Indonesia using Delphi technique. Arch Public Health 76: 70.

20. Su Ying Tsai (2013) Impact of a breastfeeding-friendly workplace on an employed mother's intention to continue breastfeeding after returning to work. Breastfeed Med 8: 210-216.

21. Weber D, Janson A, Nolan M, Li MW, Rissel C, et al. (2011) Female employees' perceptions of organisational support for breastfeeding at work: findings from an Australian health service workplace. Int Breastfeed J 6: 19

22. Chuang CH, Chang PJ, Chen YC, Hsieh WS, Hung BS, et al. (2010) Maternal return to work and breastfeeding: a population-based cohort study. Int J Nurs Stud 47(4): 461-474.

23.Van Esterik PB, Menon L (1996) Being mother-friendly: A practical guide for working women and breastfeeding. Penang: World Alliance for Breastfeeding Action 25(2): 203-208

24. (1994) Infant and young child nutrition (progress and evaluation report; and status of implementation of the International Code of Marketing of Breast-milk Substitutes). In: Report by the Director-General at the Fortyseventh World Health Assembly, World Health organization, Geneva.

25. Yimyam S, Morrow M (1999) Breastfeeding practices among employee Thai women in Chiang Mai. J Hum Lact 15(3): 225-232.

26. Tsai SY (2014) Employee perception of breastfeeding-friendly support and benefits of breastfeeding as a predictor of intention to use breastpumping breaks after returning to work among employed mothers. Breastfeed Med 9(1): 16-23.

27. Afshin Z (2017) Maternal nonstandard work schedules and breastfeeding behaviors. Matern Child Health J 21(6): 1308-1317.

28. (2008) Joint Rule for Increasing Breastfeeding at Work No. 48/MEN.PP/ XII/2008, PER. 27/MEN/XII/2008 dan 1177/MENKES/PB/XII/2008.

29. Brown CA, Poag S, Kasprzycki C (2001) Exploring large employers' and small employers' knowledge, attitudes, and practices on breastfeeding support in the workplace. J Hum Lact 17(1): 39-46.

30. Stewart Glenn J (2008) Knowledge, perceptions, and attitudes of managers, co-workers, and employed breastfeeding mothers. AAOHN J 56(10): 423-429. 
31. Wyatt SN (2002) Challenges of the working breastfeeding mother Workplace solutions AAOHN J 50(2): 61-66.

32. Yimyam S, Hanpa W (2014) Developing a workplace breast feeding support model for employed lactating mothers. Midwifery 30(6): 720 724.

33. Galtry J (1997) Lactation and the labor market: breastfeeding, labor market changes and public policy in the United States. Health Care Women Int 18(5): 467-480.

34. Cohen R, Mrtek MB, Mrtek RG (1995) Comparison of maternal absenteeism and infant illness rates among breast-feeding and formulafeeding women in two corporations. Am J Health Promot 10(2): 148153.

ISSN: 2574-1241

DOI: 10.26717/BJSTR.2020.24.004004

Yvan Vandenplas. Biomed J Sci \& Tech Res

(C) This work is licensed under Creative

Submission Link: https://biomedres.us/submit-manuscript.php
35. (2008) Health Service Executive. Breastfeeding and work [Internet]. Health Service Executive: Ireland.

36. Bar Yam NB (1998) Workplace lactation support, Part I: A return-towork breastfeeding assessment tool. J Hum Lact 14(3): 249-254.

37. Basrowi RW, Sastroasmoro S, Sulistomo AW, Bardosono S, Hendarto A, et al. (2018) Challenges and Supports of Breastfeeding at Workplace in Indonesia. Pediatr Gastroenterol Hepatol Nutr 21(4): 248-256.

38. Burns E, Triandafilidis Z (2019) Taking the path of leat resistance: a qualitative analysis of return to work or study while breastfeeding. Int Breastfeed J 14: 15. 